N.O. MCHEDLOV-PETROSSYAN,${ }^{1}$ N.N. KAMNEVA, ${ }^{1}$ A.P. KRYSHTAL,${ }^{2}$ A.I. MARYNIN ${ }^{3}$ V.B. ZAKHAREVICH ${ }^{3}$ V.V. TKACHENKO ${ }^{1}$

${ }^{1}$ Department of Physical Chemistry, V.N. Karazin National Kharkiv University (Kharkiv 61022, Ukraine)

2 Department of Physics and Technology, V.N. Karazin National Kharkiv University (Kharkiv 61022, Ukraine)

${ }^{3}$ National University of Food Technologies (68, Volodymyrs'ka Str., Kyiv 01601, Ukraine)

PACS 61.72.-y, 81.07.-b, 83.10.Rs

\title{
THE PROPERTIES OF 3 nm-SIZED DETONATION DIAMOND FROM THE POINT OF VIEW OF COLLOID SCIENCE
}

\begin{abstract}
The colloidal properties of the hydrosol of a detonation nanodiamond have been considered and discussed. The 3nm-sized positively charged colloidal species produced by the NanoCarbon Research Institute, Japan, undergo a further aggregation on the dilution. They exhibit the emission at $625 \mathrm{~nm}$ with the excitation maximum at $491 \mathrm{~nm}$, adsorb anionic dyes, and readily coagulate at the adding of electrolytes. The coagulation occurs in line with the Schulze-Hardy rule, the coagulation strength of the anions follows the Hofmeister series, whereas the abnormally high influence of the most hydrophilic anion, $\mathrm{HO}^{-}$, allows revealing the acidic character of the positive surface charge. The hypothesis of the so-called periodic colloidal structures has been put forward in order to explain the dependence of the particle size on the concentration of the hydrosol and the high viscosity of the initial $5.0 \mathrm{wt} . / \mathrm{vol}$. \% detonation nanodiamond colloid.

Keywords: detonation nanodiamonds, hydrosol, regularities of coagulation, origin of the particle charge, transmission electron microscopy, dynamic light scattering, size-concentration dependence.
\end{abstract}

\section{Introduction}

The detonation nanodiamond (DND) is one of the widely used carbon nanomaterials. Manifold applications of DND, especially in medicine, are based on its aqueous colloid solutions. To gain some insight into the DND colloid-chemical problem, we refer to a set of review papers and monographs for more details [1-5].

During the recent decade, numerous publications have been devoted to the DND behavior in aque-

(c) N.O. MCHEDLOV-PETROSSYAN, N.N. KAMNEVA, A.P. KRYSHTAL, A.I. MARYNIN,

V.B. ZAKHAREVICH, V.V. TKACHENKO, 2015 ous media. However, some problems stay undisclosed. The surface properties essentially depend on the procedures of releasing the primary diamond particles from the detonation soot, purifying the raw detonation material, and de-agglutination. The utilization of oxidizing agents, mineral acids and alkalis results in the formation of a variety of surface functional groups. Therefore, even such a fundamental characteristic as the sign of the surface charge may be different [6]. For instance, the DND with $\mathrm{COOH}$ surface groups exhibits a negative zetapotential $(\varsigma)$. However, the heating in the hydrogen atmosphere results in species with positive zeta-potential [7, 8]. Accordingly, the different stabilities of

ISSN 2071-0194. Ukr. J. Phys. 2015. Vol. 60, No. 9 
the colloids against the electrolytes of various types may be expected. Note that the colloidal species of another nanocarbon material, the entire fullerene, are always negatively charged both in water and in polar anhydrous solvents [9]. Whereas, in the case of hydrosols, the adsorption of the $\mathrm{HO}^{-}$ions (or, otherwise, the concept of the localized hydrolysis) is the most probable reason, the origin of the negative charge of fullerene colloidal particles in polar nonhydrogen bond donor solvents is less clear [9]. For instance, it may be caused by the formation of ionradicals in fullerene solutions.

The $\varsigma$ values of the DND colloidal species of different origin strongly depend on the $\mathrm{pH}$ of bulk water, thus revealing the protolytic (acid-base) origin of the interfacial charge. Though some methods, first of all, the vibrational spectroscopy, are used for the identification of surface groups, the DND hydrosols reported up to now should be considered as ill-defined colloidsfrom the viewpoint of the interfacial properties.

Though the $\varsigma$ values become more positive (less negative) in acidic media and less positive in alkaline solutions, the "positive" colloidal particles of some types of DND retain their charge sign even at $\mathrm{pH}$ 11$12[8,10-13]$. On the other hand, some DND samples with other histories undergo the re-charging of their particles in alkaline media $[6,10,13,14]$.

Therefore, it is worth regarding presently the colloidal-chemical properties of each kind of the DND hydrosol separately. As an example, below, we consider the colloid properties and the behavior of the aqueous dispersion of a DND hydrosol very recently produced in the NanoCarbon Research Institute, Ltd, Asama Research Extension Center, Faculty of Textile Science and Technology, Shinshu University, Japan. The sample in the form of a $5.0 \mathrm{wt} . / \mathrm{vol} . \%$ aqueous colloid solution was kindly donated by Professor Eiji Osawa.

\section{Colloid-Chemical Properties of DND Hydrosol}

\subsection{Characterization of the sample}

This sample, as well as one studied earlier [15], has been prepared in the NanoCarbon Research Institute from the raw DND received from the FMD Nano Tech Co., Guangzhou, China without use of any chemicals, via the attrition milling with $30 \mu \mathrm{m}$ $\mathrm{ZrO}_{2}$ beads as an attritter in distilled water. After de-agglutination, the solution was slightly acidic with
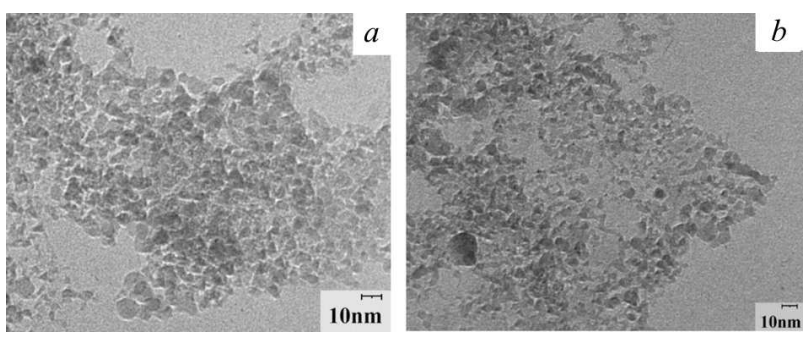

Fig. 1. TEM images of the evaporated DND hydrosols examined previously [15] (a) and in the present study (b)

pH 4.6 to 5.0. The $3 \mathrm{~nm}$-sized species exhibit fluorescence with maximum at $625 \mathrm{~nm}$, originating probably from the crystal lattice defects of $\mathrm{N}-\mathrm{V}$ type; the emission excitation maximum at $491 \mathrm{~nm}$, just near the line of the argon-ion laser (488 nm) [15]. The particle size used below has been determined by the dynamic light scattering, DLS, (Zetasizer Nano ZS Malvern Instruments) and the transmission electron microscopy (Selmi TEM-125K microscope). The average particle size in a 5.0 wt. $/$ vol. \% hydrosol is $2.7 \pm 0.6 \mathrm{~nm}$ (distribution by particle number) and $3.4 \pm 0.6 \mathrm{~nm}$ (by volume), as determined via DLS. The electron diffraction patterns reveal a diamond lattice of the sample. The lattice parameter was measured as $0.375 \pm 0.002 \mathrm{~nm}$, and it coincides with the tabulated values for diamond within the error margins. The TEM images of the evaporated DND hydrosol with concentrations of 0.0036 to 0.036 wt. $/$ vol. \% are typified in Fig. 1.

The charge of DND particles in aqueous solutions is positive. The zeta-potential values vary within the range of ca. $+(40-60) \mathrm{mV}$, depending on the concentration. For DND hydrosols of the same type, studied previously [15], the qualitative reaction with $\mathrm{Ag}^{+}$, utilization of $\mathrm{Cl}$-selective electrodes in a solution and EDX spectroscopy for the evaporated samples allowed us to state that $\mathrm{Cl}^{-}$ions are counterions in this colloid system.

In accordance with the positive charge of DND particles, the absorption bands of anionic dyes in water undergo a substantial bathochromic shift after introducing the ND colloid, typical of the interaction of these chromophores with cationic colloidal particles of different types [15]. In Fig. 2, the new data for 4,5dinitrosulfonefluorescein and eosin are demonstrated.

One of the most interesting peculiarities of the DND particles under study is the increase in size on the dilution of a hydrosol, evidently due to the ag- 

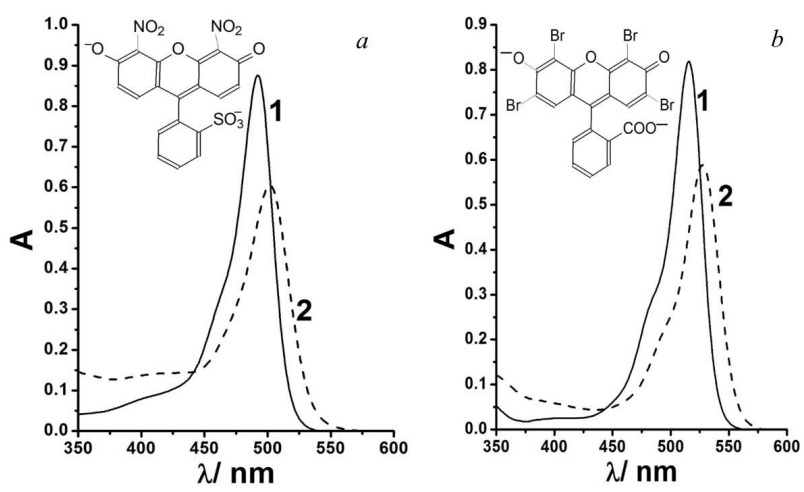

Fig. 2. 4,5-Dinitrosulfonefluorescein (a) and eosin (b) in water (1) and in ND 0.048 wt./vol.\% solution (2); $\mathrm{pH} 6.64,25^{\circ} \mathrm{C}$

gregation of primary species. The size of colloidal aggregates in the extremely diluted solutions is ca. tenfold higher as compared with that of the small primary particles observed in the $5.0 \mathrm{wt} . /$ vol. \% initial hydrosol. This phenomenon will be discussed below.

\subsection{Coagulation regularities, the origin of the surface charge, and aging of the DND hydrosol}

The behavior of the ND hydrosol in the presence of electrolytes should be explained in terms of the rules of colloid chemistry of hydrophobic dispersions. The critical coagulation concentrations (CCC) upon the addition of electrolytes have been determined, by using the sharp absorbance increase in the visible range due to the turbidity caused by the impetuous rise in the size of particles. Normally, the uncertainty of the CCC values does not exceed $\pm(10-15) \%$. Simultaneously, the dynamic light scattering indicates the distinct growth of colloidal species just under the same threshold condition. The CCCs reveal no serious dependence on the ND concentration; the most data were obtained with $0.13-0.19$ wt./vol.\% hydrosol.

The coagulation by inorganic salts occurs in line with the sign of the charge of colloidal species. The classical Schulze-Hardy rule predicts a sharp increase in the coagulation power of multicharged wellhydrated inorganic anions in the case of "positive" sols. Indeed, the ratio of the reciprocal CCC values for the anions $\mathrm{Cl}^{-}, \mathrm{SO}_{4}^{2-}, \mathrm{Fe}(\mathrm{CN})_{6}^{3-}$, and $\mathrm{Fe}(\mathrm{CN})_{6}^{4-}$ is $1: 16:(175$ to 200$):(538$ to 583$)$, as determined in several independent series of experiments. The consideration of the DND hydrosol stability in terms of the Derjaguin-Landau-Verwey-Overbeek theory has been made in our previous paper [15].

The influence of anions upon the stability of the hydrosol is in line with the so-called lyotropic row or Hofmeister series. Whereas the nature of a cation is of no importance, the single-charged anions are arranged in respect to their coagulation strengths in accordance with their Gibbs energies of hydration, $\Delta G_{\text {hydr }}: \mathrm{Cl}^{-}(-347)<\mathrm{Br}^{-}(-321)<\mathrm{ClO}_{4}^{-}(-214)$. The $\Delta G_{\text {hydr }}$ values are expressed in $\mathrm{kJ} \mathrm{mol}^{-1}$ [16]. The coagulation strength of the extremely hydrophobic tetraphenylborate anion is 100 -fold higher as compared with that of $\mathrm{Cl}^{-}$, which follows from the CCC values for $\mathrm{NaB}\left(\mathrm{C}_{6} \mathrm{H}_{5}\right)_{4}$ and $\mathrm{NaCl}$.

Though the hydroxyl ion is the most hydrophilic one among the ones studied here $\left(\Delta G_{\mathrm{hydr}}=\right.$ $=-439 \mathrm{~kJ} \mathrm{~mol}^{-1}$ ) [16], the coagulation strength of $\mathrm{NaOH}$ exceeds that of $\mathrm{NaCl}$ ca. ten-fold [15]. This finding was repeatedly observed for DND samples of different production lots from NanoCarbon Research Institute and unequivocally reveals the acidic nature of the surface charge.

As was shown previously [15], once coagulated by $\mathrm{NaOH}$, the sol undergoes no peptization on the dilution with water, contrary to the deposit obtained by $\mathrm{NaCl}$. Only the neutralization of alkali by equivalent amount of acid restores the sol.

There are different explanations of the origin of the surface charge of colloid DND species obtained via various procedures $[3,10-13,17]$. In the case of particles with $\varsigma>0$, the protonated amino and ether groups and pyrones seem to be the most likely. The IR and Raman spectra allow assuming the presence of such groups on the surface [15]. Moreover, the presence of the non-diamond (graphitic) layer is often assumed [11, 18, 19]. However, as the de-agglutination of the DND under study has been made without using any chemicals, it is possible to consider the attaching of hydrated protons, $\mathrm{H}_{3} \mathrm{O}^{+}$, or $\mathrm{H}_{5} \mathrm{O}_{2}^{+}$, etc., to the electro-negative facets of the DND surface as a possible reason for the positive charging.

For the coagulation by $\mathrm{NaCl}$, the $\mathrm{CCC}$ is equal to $2.8 \pm 0.3 \mathrm{mM}$ (hereafter, $1 \mathrm{mM}=0.001$ mole $\mathrm{dm}^{-3}$ ). This value has been determined for the freshly obtained DND hydrosol and stayed constant during almost a year [15].

However, about one year after the preparation of the sol, the CCC values began to rapidly decrease. For instance, for $\mathrm{NaCl}, \mathrm{CCC}=0.33-0.46 \mathrm{mM}$ as de- 
termined for a $0.19 \%$ colloidal solution. The CCC value for $\mathrm{HCl}$, however, stays unaffected $(5.7 \mathrm{mM})$. Moreover, the small addition of hydrochloric acid to the sol restores the $\mathrm{CCC}$ value for $\mathrm{NaCl}$. In the presence of $0.148 \mathrm{mM} \mathrm{HCl}$, the $\mathrm{CCC}$ value with $\mathrm{NaCl}$ is elevated up to $2.61-2.83 \mathrm{mM}$. At $0.19 \mathrm{mM} \mathrm{HCl}$, $\mathrm{CCC}(\mathrm{NaCl})=3.67 \mathrm{mM}$. Probably, the protonation of some basic centers on the surface enhances the stability of the DND hydrosol.

It should be noted that, though the main properties of the DND colloid manufactured in NanoCarbon Research Institute do not vary from one production lot to another, the CCC values appeared to be somewhat different. Probably, this is caused by some modifications of the preparation procedure. So, for the new sample of the ND hydrosol, examined by us very recently, the $\mathrm{CCC}$ value for $\mathrm{NaCl}$ was substantially lower: $1.29 \mathrm{mM}$. Again, in the presence of $0.099,0.196$, and $0.22 \mathrm{mM} \mathrm{HCl}$, the critical concentration of $\mathrm{NaCl}$ increases to $3.47,4.25$, and $4.25 \mathrm{mM}$, respectively.

On the other hand, the $\mathrm{CCC}$ value for $\mathrm{NaOH}$ for the new sample is $0.153 \mathrm{mM}$, so the ratio of $\mathrm{CCC}(\mathrm{NaCl})$ : $\mathrm{CCC}(\mathrm{NaOH})$ is with 8.4 rather close to that determined with the previous sample (10.4) [15].

\subsection{Size increase of $D N D$ species on the dilution: in search for a reasonable explanation}

The concentrated aqueous solutions of $3 \mathrm{~nm}$-sized DND particles are rather viscous. Using the value of the ND density of $3.17 \mathrm{~g} \mathrm{~cm}^{-3}$, one can estimate that the volume fraction of the dispersed phase of the $5.0 \mathrm{wt} . / \mathrm{vol} . \%$ hydrosol is $1.6 \%$. Hence, occupying less than $2 \%$ of the total volume of the hydrosol, the species cause the ca. two-fold increase in the viscosity [15]. The high viscosity of concentrated DND hydrosols has been also observed previously by others [20]. Meanwhile, if the species are assumed to be spherical, the viscosity should increase no more than by $4 \%$ as compared with that of pure water according to the well-known Einstein equation. It should also be taken into account that, at 8-12 wt./vol.\%, the hydrogel is already formed. Hence, the water layers inbetween the small colloidal DND species seem to be fixed in some unknown way. Naturally, on the dilution, the viscosity decreases up to that in pure water at 0.03 wt. $/$ vol. $\%$ DND.

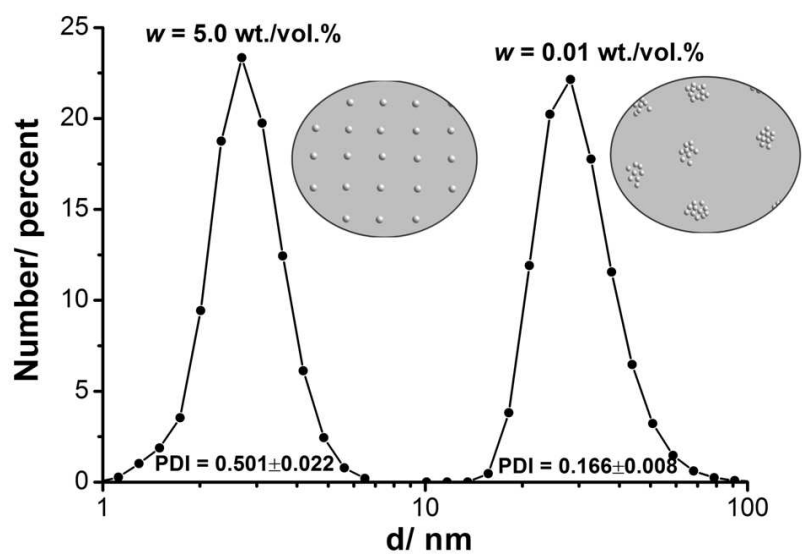

Fig. 3. Size distribution of a $5.0 \mathrm{wt} . / \mathrm{vol} . \%$ colloidal ND solution and a diluted, 0.01 wt./vol.\% ND solution; inset: the schematic picture of the solution structure
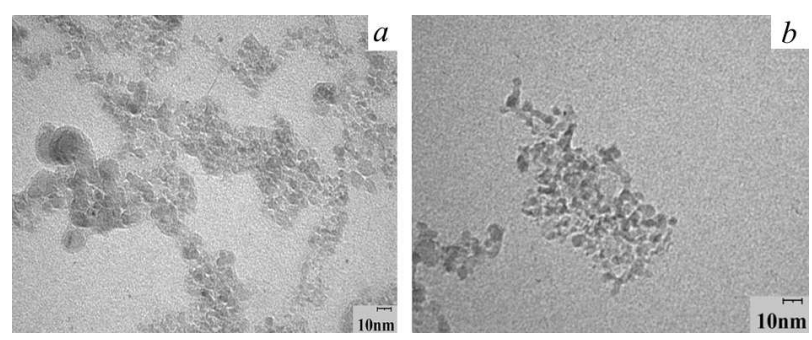

Fig. 4. TEM images of the evaporated 0.036 wt./vol.\% DND hydrosols, as obtained by the dilution of a $5.0 \mathrm{wt} . / \mathrm{vol} . \% 1.5$ year-aged sol $(a)$ and of the very recently produced initial sol of the same concentration $(b)$

At the same time, we found that the size distribution of the dispersed system is strongly concentrationdependent: the dilution enlarges the species up to one order of magnitude. The results obtained with the new fresh sample of DND hydrosol are exemplified in Fig. 3. They give support for the observation obtained previously with another production lot [15].

This phenomenon may be explained in terms of the so-called periodic colloidal structures [21-23] formed in concentrated solutions of highly solvated and very large colloids. For such systems, where the particles interact through the surrounding water layers, some peculiarities have been noticed long ago, mostly for much larger particles of the dispersed phase [2123]. The "secondary" or "distant" minimum, resulting from the cooperative interactions, may be deeper as compared with that calculated from the interaction of two particles only. Namely, the fixation of parti- 
cles without direct contact may take place even if the repulsive forces overcome the attractive ones. The 4 to $5 \mathrm{wt}$./vol.\% hydrosol may be considered as a colloidal system being on the way to gelation. (At $8-12 \%$ DND, the hydrogel is formed.)

On the dilution accompanied by the stirring of the system, the distances between the particles became larger, the cooperative interactions being weaker, and the entropy factor $(\Delta S>0)$ favors the uniform distribution of species in the enlarged volume. This results in destroying such quasi-equilibrated state, and the (probably stepwise) aggregation takes place owing to the hydrophobic and interfacial Coulombic [19] interactions and van der Waals (dispersive) forces. Instead of the network of small particles, larger aggregates are formed as a result of the tight interaction of several neighboring primary particles. The further aggregation is hindered by expanding the diffuse parts of the double electrical layers around the aggregates.

The state of the hydrosol is shown in Fig. 3 in a simplified manner. But the zones of a periodic colloidal structure do not necessarily cover the whole solution. For the previously studied sol [15], the polydispersity index, PDI, gradually increased along with the dilution from PDI $=0.590$ for $5.0 \mathrm{wt} . / \mathrm{vol} . \%$ to 0.190 for 0.036 wt. $/$ vol.\%. For the presently examined hydrosol, PDI $=0.501$ and 0.166 for 5.0 and 0.01 wt./vol.\%, respectively. Probably, some numbers of very large islands of associated secondary species are also present in concentrated sols, as is demonstrated by the DLS measurements in the intensity-size distributions.

The slight aging of the concentrated sol results an increase in sizes and a decrease in the viscosity after the storing for several months.

On the other hand, in the case of the freshly produced DND hydrosol, the increase in the size along with dilution occurs not so sharply, though the aggregates in the extremely diluted systems are also ca. $30 \mathrm{~nm}$-sized (Fig. 3). The TEM images of aged and fresh diluted hydrosols are similar in outline. However, in the first case, the primary species look out somewhat more bound together (Fig. 4).

The hypothesis of periodic colloidal structures seems to be reasonable. However, the studies of different DND hydrosols via the method of smallangle neutron scattering (SANS) have lead to another model [24-26]. In these publications, the fractal structure of the aggregates (or clusters) has been pro- posed; the 'light' and 'heavy' clusters have been isolated with the help of the centrifugation/fractionation procedure [26]. The fractal structure of the aggregates was also stated in other papers [27, 28]; such character of association does not contradict our vision of aggregates in diluted DND solutions. As for the structure of the concentrated $5.0 \mathrm{wt} . / \mathrm{vol} . \% \mathrm{so}-$ lutions, the further comparison of the data obtained for the same DND hydrosol by DLS, SANS, and also by differential scanning calorimetry $[29,30]$ and ${ }^{1} \mathrm{H}$ NMR magnetic relaxation spectroscopy [31] seems to be promising. For instance, the above-mentioned fractal clusters may be in fact regions of periodic colloidal structures.

\section{Conclusions}

The concentrated 5.0 wt./vol.\% DND hydrosol produced in the NanoCarbon Research Institute, Japan, is a polydisperse colloidal system with predominance of small primary particles with an average diameter of $2.7 \pm 0.6 \mathrm{~nm}$, as determined by the dynamic light scattering. The coagulation by different electrolytes reveals that the classical Schulze-Hardy rule holds for this hydrosol, whereas the strong coagulation by alkali indicates the acidic nature of the positive charge of the colloidal species. Moreover, the colloid stability against the electrolytes decreases along with the aging of the sol and may somewhat vary from one initial sample to another, depending on some modifications of the preparation procedure. Interestingly, the decreased critical coagulation concentrations may be restored by the introduction of $\mathrm{HCl}$ in low concentrations.

In order to explain the high viscosity of the initial $5.0 \mathrm{wt} . / \mathrm{vol} . \%$ hydrosol and the aggregation of the DND primary particles on the dilution, the concept of periodic colloidal structures is used.

We thank Professor Eiji Osawa, NanoCarbon Research Institute, for his generous gift of the DND hydrosol.

1. E. Osawa, in Handbook of Advanced Ceramics: Materials, Applications, Processing and Properties, edited by S. Soumiya (Elsevier, Amsterdam, 2013), Chapter 2.3, p. 89.

2. E. Osawa, Pure Appl. Chem. 80, 1365 (2008).

3. V.N. Mochalin, O. Shenderova, D. Ho, and Y. Gogotsi, Nature Nano 7, 11 (2012).

ISSN 2071-0194. Ukr. J. Phys. 2015. Vol. 60, No. 9 
4. O.A. Shenderova and D.M. Gruen, in Ultrananocrystalline Diamond: Synthesis, Properties and Applications, edited by D.M. Gruen, O.A. Shenderova (Elsevier, Oxford, 2012).

5. E. Osawa, S. Sasaki and R. Yamanoi, in Ultrananocrystalline Diamond: Synthesis, Properties and Applications, edited by D.M. Gruen, O.A. Shenderova (Elsevier, Oxford, 2012).

6. N. Gibson, O. Shenderova, T.J.M. Luo, S. Moseenkov, V. Bondar, A. Puzyr, K. Purtov, Z. Fitzgerald and D.W. Brenner, Diamond and Related Mater. 18, 620 (2009).

7. M. Ozawa, M. Inaguma, M. Takahashi, F. Kataoka, A. Krüger, and E. Osawa, Adv. Mater. 19, 1201 (2007).

8. O.A. Williams, J. Hees, C. Dieker, W. Jäger, L. Kirste, and C. E. Nebel, ACS Nano, 4, 4824 (2010).

9. N.O. Mchedlov-Petrossyan, Chem. Rev. 113, 5149 (2013).

10. T. Petit, J.C. Arnault, H.A. Girard, M. Sennour, T.Y. Kang, C.L. Cheng, and P. Bergonzo, Nanoscale 4, 6792 (2012).

11. J.T. Paci, H.B. Man, B. Saha, D. Ho, and G.C. Schatz, J. Phys. Chem. C 117, 17256 (2013).

12. J. Hees, A. Kriele, and O.A. Williams, Chem. Phys. Lett. 509, 12 (2011)

13. X. Xu, Z. Yu, Y. Zhu, and B. Wang, Diamond and Related Mater. 14, 206 (2005).

14. N. Gibson, T.-J. Luo, O. Shenderova, A. Koscheev, and D. Brenner, J. Nanoparticle Res. 14, 1 (2012)

15. N.O. Mchedlov-Petrossyan, N.N. Kamneva, A.I. Marynin, A.P. Kryshtal, and E. Osawa, Phys. Chem. Chem. Phys. 17, 16186 (2015).

16. Y. Marcus, Langmuir 29, 2881 (2013).

17. A. N. Zhukov, F. R. Gareeva, and A. E. Aleksenskii, Colloid J. 74, 463 (2012).

18. A.S. Barnard, J. Mat. Chem. 18, 4038 (2008).

19. A.S. Barnard and E. Osawa, Nanoscale 6, 1188 (2014).

20. A.Y. Vul, E. D. Eydelman, M. Inakuma, and E. Osawa, Diamond and Related Mater. 16, 2023 (2007).

21. I.F. Efremov, Periodic Colloidal Structures (Khimiya, Leningrad, 1971) (in Russian).

22. I.F. Efremov and O.G. Us'yarov, Russ. Chem. Rev. 45, 435 (1976).

23. H. Sonntag, K. Strenge, and B. Vincent, Coagulation Kinetics (Springer, New York, 1987).

24. M.V. Avdeev, N. N. Rozhkova, V.L. Aksenov, V.M. Garamus, R. Willumeit, and E. Osawa, J. Phys. Chem. C 113, 9473 (2009).
25. M.V. Avdeev, V.L. Aksenov, O.V. Tomchuk, L.A. Bulavin, V.M. Garamus, and E. Osawa, J. of Phys. Conden. Matter 25, 445001 (2013).

26. O.V. Tomchuk, D.S. Volkov, L.A. Bulavin, A.V. Rogachev, M.A. Proskurnin, M.V. Korobov, and M.V. Avdeev J. Phys. Chem. C 119, 794 (2015).

27. M.V. Avdeev, N.N. Rozhkova, V.L. Aksenov, V.M. Garamus, R. Willumeit, and E. Osawa, J. Phys. Chem. C 113, 9473 (2009).

28. F. Gareeva, N. Petrova, O. Shenderova, and A. Zhukov, Coll. Surf. A: Phys. Chem. Eng. Asp. 440, 202 (2014).

29. M.V. Korobov, M.M. Batuk, N.V. Avramenko, N.I. Ivanova, N.N. Rozhkova, and E. Osawa, Diamonds and Related Mater. 19, 665 (2010).

30. M.V. Korobov, D.S. Volkov, N.V. Avramenko, L.A. Belyaeva, P.I. Semenyuk, and M.A. Proskurnin, Nanoscale 5, 1529 (2013).

31. A. M. Aparkin, G.V. Nazarov, V.A. Zlobin, P.E. Kuznetsov, S.M. Rogacheva, and I.A. Sogunenko, Colloid J. 65, 725 (2003).

Received 08.06.15

М.О. Мчедлов-Петросян,

Н.М. Камнева, О.П. Кришталь, А.І. Маринін,

В.Б. Захаревич, В.В. Ткаченко

ВЛАСТИВОСТІ НАНОРОЗМІРНОГО (3 нм)

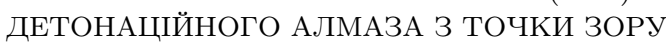

КОЛӦ̈ДНОЇ НАУКИ

$\mathrm{P}$ е $з$ ю м е

Розглянуто та обговорено колоїдні властивості гідрозоля детонаційного наноалмаза. Позитивно заряджені колоїдні частинки розміром 3 нм, вироблені у NanoCarbon Research Institute (Японія), утворюють агрегати при розведенні розчину. Колоїдні частинки флуоресціюють 3 максимумом смуги випромінювання при 625 нм (максимум смуги збудження 491 нм), адсорбують на своїй поверхні аніонні барвники і легко коагулюють під впливом електролітів. Коагуляція проходить у відповідності з правилом Шульце-Гарді, а коагулююча сила однозарядних аніонів підпорядковується закономірності, що випливає з "ряду Гофмейстера", в той час як аномально сильний вплив найбільш гідрофільного з аніонів, $\mathrm{HO}^{-}$, дозволяє виявити кислотну природу позитивного поверхневого заряду колоїдних частинок. Для інтерпретації концентраційної залежності розмірів колоїдних частинок і високої в'язкості вихідного 5\%-ного колоїдного розчину запропоновано гіпотезу, основану на концепції так званих періодичних колоїдних структур. 